\title{
田
}

\section{AS DIRETRIZES CURRICULARES DA ABEPSS E OS VALORES ÉTICOS E POLÍTICOS PARA A FORMAÇÃO PROFISSIONAL EM SERVIÇO SOCIAL}

\author{
THE CURRICULUM GUIDELINES OF ABEPSS AND ETHICAL VALUES AND \\ POLITICAL AFFAIRS FOR VOCATIONAL TRAINING IN SOCIAL SERVICE
}

\author{
Tales Willyan Fornazier Moreira ${ }^{1}$ \\ Lesliane Caputi
}

\section{RESUMO}

O presente artigo é oriundo das construções e reflexões acerca do Projeto Ético-Político no âmbito da Formação Profissional em Serviço Social. Objetiva refletir sobre a importância do fortalecimento do projeto de Formação Profissional hegemônico da categoria, nos marcos da púbere direção social, ética e política da profissão, engendrada na teoria social marxista, na perspectiva de intenção de ruptura, enfatizando as Diretrizes Curriculares da ABEPSS de 1996 enquanto referência para a formação nesta proposta crítica. Finda com reflexões que abalizam desafios presentes na atual contextura e a tarefa imperativa das entidades da categoria (ABEPSS, CFESS/CRESS e ENESSO) na construção de ações políticas e coletivas unificadas com as bases, com vistas ao fortalecimento deste projeto de formação que confere também a um projeto de sociedade.

Palavras Chave: Serviço Social. Formação Profissional. Diretrizes Curriculares da ABEPSS. Projeto Ético-Político.

\footnotetext{
1 Assistente Social, graduado pela Universidade Federal do Triângulo Mineiro/UFTM. Integrante do Grupo de Estudo e Pesquisa em Fundamentos, Formação e Exercício Profissional em Serviço Social/GEFEPSS da UFTM.

2 Assistente Social, Mestre e Doutora em Serviço Social. Docente do Departamento de Serviço Social da UFTM. Líder do Grupo de Estudo e Pesquisa em Fundamentos, Formação e Exercício Profissional em Serviço Social/GEFEPSS da UFTM.
} 


\section{temporollis}

\section{ABSTRACT}

This article comes from the buildings and reflections on the Ethical-Political Project under the Vocational Training in Social Work. Aims to reflect on the importance of strengthening the hegemonic Vocational Training project category, in the framework of pubescent social direction, ethics and politics of the profession, engendered in Marxist social theory, the prospect of breaking intent, emphasizing the Curriculum Guidelines 1996 ABEPSS as a reference for training in this critical proposal. Ends with reflections mark challenges present in the current texture and imperative task of the category entities (ABEPSS, CFESS / CRESS and ENESSO) in building policies and collective actions unified with the foundation, in order to strengthen this training project which also gives a project of society.

Keywords: Professional Training in Social Work. Curriculum Guidelines ABEPSS. Ethical-Political Project.

Submissão - 29/08/2016 Aceite - 13/01/2017

\section{Introdução}

O debate acerca das Diretrizes Curriculares da Associação Brasileira de Ensino e Pesquisa em Serviço Social (ABEPSS) de 1996, enquanto sustentáculo ético e político para a Formação Profissional na perspectiva de intenção de ruptura, tendo como referência a teoria social de Marx, se faz mister, sobretudo, em tempos de agudizamento da lógica da educação perpetrada sob a égide da ofensiva neoliberal.

O contexto de flexibilização, precarização, aligeiramento e mercantilização da educação causa rebatimentos diretos na formação em Serviço Social, e nos convoca a uma vigília permanente do projeto de Formação Profissional que defendemos.

Tal projeto é calcado nos valores éticos presentes nas Diretrizes Curriculares da ABEPSS e não nas Diretrizes aprovadas e encaminhadas pelo Conselho Nacional de Educação (CNE) e Ministério da Educação (MEC) - as quais suprimem elementos essenciais da proposta de formação construída coletivamente pela categoria, sobremaneira, no que se refere à direção social da formação, aos conhecimentos e habilidades fundamentais para desempenho da profissão de assistente social. (IAMAMOTO, 2014).

A Formação Profissional é objeto de preocupação permanente das entidades da categoria, a destacar nos tempos atuais de tamanhos retrocessos à ofensiva neoconservadora, ao neofacismo e a op- 
ção pós-moderna, em que a luta coletiva deve ser travada ainda que seja fácil ceder.

Esta discussão, na perspectiva de intenção de ruptura, apresenta as significâncias do Projeto Ético-Político profissional, no sentido de expressar os valores éticos e políticos que delineiam não só a formação em Serviço Social em solo brasileiro, mas também a construção de outra sociabilidade. Tal projeto deriva dos desdobramentos do Movimento de Reconceituação, enquanto construção coletiva de novas bases de legitimação da profissão, que contribuíram, fundamentalmente, para a elaboração das Diretrizes Curriculares do Serviço Social no Brasil, com proposta de formação generalista, numa perspectiva de totalidade da realidade social.

Este projeto hegemônico e não homogêneo, reafirma a perspectiva crítica da categoria com a Formação Profissional e exige de nós um verdadeiro convite à rebeldia, para que possamos construir, coletivamente, as mediações necessárias para o seu robustecimento nestes tempos tão "temerosos".

\section{Projeto ético-político e o debate da formação profissional}

Para a compreensão da proposta de formação profissional de assistente sociais, expressa nas Diretrizes Curriculares (DCs) da ABEPSS de 1996, bem como todo seu significado ético, político e ideológico, faz-se necessário a historicização acerca da construção do projeto profissional hegemônico da categoria. A partir da apreensão de como o mesmo se constituiu e se configura, entendemos ser possível interpretar os valores éticos centrais, que edificam a púbere configuração da formação, expressa nestas Diretrizes.

A formação profissional, construída e gestada pela categoria no Brasil, teve como força motriz, o processo de renovação do Serviço Social, o qual teve como marco o Movimento de Reconceituação da profissão em nível latino-americano. Este movimento possibilitou que a profissão caminhasse para a superação do monopólio conservador no âmago profissional e construísse bases de legitimação, vinculadas à perspectiva de intenção de ruptura. Este processo se inicia em meados da década de 1960 , quando a profissão adentra num movimento de questionar sua intervenção na realidade e sua contribuição na superação do subdesenvolvimento. Tal movimento, longe 


\section{temporollis}

de possuir uma homogeneidade, é demarcado pela constituição de três tendências no seio profissional: vertente modernizadora; reatualização do conservadorismo e intenção de ruptura. ${ }^{3}$ (PAULO NETTO, 2010). Contudo, é a vertente de intenção de ruptura que possibilita a interlocução com a teoria marxista na década de 1980 e seu amadurecimento na década seguinte, e propicia os elementos teóricos, éticos e políticos fundamentais para a conformação do atual projeto profissional hegemônico do Serviço Social brasileiro.

Este projeto é denominado como Projeto Ético-Político (PEP), o qual, concorde com José Paulo Netto (1999), se estrutura a partir do processo da recusa e crítica ao conservadorismo na profissão; rejeita os ideários conservadores - que foram referência para o Serviço Social tradicional desde sua gênese no país - e se vincula a outra perspectiva de formação e exercício profissional que, não obstante, também está alinhada a um ideal de projeto societário a ser construído.

Tal autor concebe os projetos societários como projetos coletivos que apresentam uma imagem de sociedade a ser construída, ou seja, se configuram como a idealização de um modelo de sociabilidade. Os projetos societários possuem a peculiaridade de se apresentarem enquanto projetos macroscópicos, evidenciando um conjunto de valores a serem gestados para a construção de uma nova ordem social, ou, num polo oposto, para a manutenção do modo de produção operante.

Um projeto de sociedade também se configura como um projeto de classe, por explicitar a perspectiva ideopolítica do coletivo que o constrói, possibilitando a correlação de forças, bem como a disputa de interesses presentes nos diversos projetos societários. A esse despeito, é fundamental que haja a liberdade política, pois:

\footnotetext{
É somente quando se conquistam e se garantem as liberdades políticas fundamentais (de expressão e manifestação do pensamento, de associação, de votar e ser votado etc.) que distintos projetos societários podem confrontar-se e disputar a adesão dos membros da sociedade (PAULO NETTO, 1999, p. 3).
}

Quando falamos de liberdades políticas fundamentais, esta-

3 Para maior aprofundamento, ver Netto (2010). 


\section{temporolis}

mos nos referindo a uma concepção de Estado Democrático de Direito limitado, muito aquém dos reais interesses e necessidades da classe trabalhadora. Referimo-nos às conquistas de direitos necessários, entretanto, construídos dentro da lógica burguesa, e que não trazem, de fato, uma perspectiva de rompimento com o sistema de exploração do capital, com a construção da emancipação política e, tampouco, da emancipação humana.

Historicamente, quando pensamos na concepção de um projeto societário que represente os interesses da classe trabalhadora, este sempre sofre os rebatimentos da cooptação, do abafamento político, da deslegitimação e é pressionado a se sucumbir à ordem vigente - mesmo que vivamos num contexto de "democracia". Conforme nos alude o professor José Paulo Netto (1999, p. 3):

[...] na ordem do capital, por razões econômico-sociais e culturais, mesmo num quadro de democracia política, os projetos societários que respondem aos interesses das classes trabalhadoras e subalternas, sempre dispõem de condições menos favoráveis para enfrentar os projetos das classes proprietárias e politicamente dominantes.

Entendendo as correlações de forças, bem como as contradições presentes nos diversos projetos societários e que, num todo, as demandas da classe trabalhadora tendem a ser silenciadas, se faz mister o fortalecimento de projetos coletivos que se coloquem na contramão do sistema do capital. Nesta direção, o PEP enquanto projeto profissional hegemônico do Serviço Social, que se vincula à construção de uma sociedade anticapitalista, é imprescindível.

Cabe dizer que os projetos profissionais, também são projetos coletivos e, não obstante, se articulam e propõem a construção e/ou fortalecimento de um determinado projeto de sociedade. Tais projetos se circunscrevem no âmbito de uma dada profissão, elucidando suas características e valores. Assim,

[...] delimitam e priorizam seus objetivos e funções, formulam os requisitos (teóricos, práticos e institucionais) para o seu exercício, prescrevem normas para o comportamento dos profissionais e estabelecem as bases de suas relações com os usuários de seus serviços, com as outras profissões e com as organizações e instituições sociais privadas e públicas. (PAULO NETTO, 1999, p. 4). 


\section{temporollis}

Infere-se, pois, que estes projetos espelham a atuação e a perspectiva teórica, ética, ideológica e política de determinada profissão, não se tratando de um espaço isento de disputas e contradições, haja vista que, conforme Paulo Netto (1999, p. 5), “[...] todo corpo profissional é um campo de tensões e de lutas. A afirmação e consolidação de um projeto profissional em seu próprio interior não suprimem as divergências e contradições."

Pensando no PEP enquanto projeto hegemônico e não homogêneo, significa dizer que há outros projetos profissionais que disputam hegemonia no âmago do Serviço Social. Sendo assim, se faz necessário que o coletivo de profissionais que acreditam neste projeto hegemônico, atrelado à outra sociabilidade - livre de exploração, desigualdade, dominação, opressão e injustiça social - possam construir mediações para o seu fortalecimento considerando a sua clara direção política:

A dimensão política do projeto é claramente anunciada: ele se posiciona a favor da equidade e da justiça social, na perspectiva da universalização do acesso a bens e a serviços relativos às políticas e programas sociais; a ampliação e consolidação da cidadania são explicitamente postas como garantia dos direitos civis, políticos e sociais das classes trabalhadoras. Correspondentemente, o projeto se declara radicalmente democrático - considera a democratização como socialização da participação política e socialização da riqueza socialmente produzida. (PAULO NETTO, 1999, p. 16).

O projeto se configura como um horizonte estratégico a ser alcançado, traz uma perspectiva de projeto societário a ser construído. Destarte, os projetos profissionais não podem ser concebidos descolados de uma perspectiva macrossocietária, haja vista que os interesses que permeiam também trazem um posicionamento eminentemente político: ou em defesa dos direitos dos/as trabalhadores/as, galgando para a transformação radical desta sociabilidade ou, antagonicamente, em defesa da manutenção da ordem do capital e todas as suas consequências nefastas à classe trabalhadora, como a proposta da ofensiva neoliberal.

Na mesma proporção, não podem ser concebidos como algo pré-estabelecido, determinado e acabado, pois:

Os projetos profissionais também são estruturas di- 


\section{tempordilis}

nâmicas, respondendo às alterações no sistema de necessidades sociais sobre o qual a profissão opera às transformações econômicas, históricas e culturais, ao desenvolvimento teórico e prático da própria profissão e, ademais, às mudanças na composição social do corpo profissional. Por tudo isto, os projetos profissionais igualmente se renovam, se modificam. (PAULO NETTO, 1999, p. 5).

Concorde Marcelo Braz (2008), a materialidade do PEP se viabiliza em três elementos constitutivos e essenciais, a saber: I - dimensão da produção científica da categoria: diz respeito a toda produção de conhecimento e sistematização das ações profissionais, seja na academia ou em outros espaços sócio-ocupacionais; II - dimensão político-organizativa: refere-se à militância e todos os espaços deliberativos e de representações na categoria, seja no conjunto Conselho Federal de Serviço Social (CFESS) e do Conselho Regional de Serviço Social (CRESS), na ABEPSS ou na Executiva Nacional dos Estudantes de Serviço Social (ENESSO); III - dimensão jurídico-política: entendida como o conjunto de leis, resoluções, documentos e textos políticos que balizam a atuação profissional como, por exemplo: Código de Ética Profissional (1993), Lei de Regulamentação da profissão n 8.662/1993, Diretrizes Curriculares de 1996, Constituição Federal de 1988, Resoluções do Conjunto CFESS/CRESS, dentre outros.

\footnotetext{
Essas dimensões articuladas entre elas compõem o corpo material do projeto ético político profissional que, como foi dito, deve ser compreendido como uma construção coletiva que, como tal, tem uma determinada direção social que envolve valores, compromissos sociais e princípios que estão em permanente discussão exatamente porque participante que é do movimento vivo e contraditório das classes na sociedade. (BRAZ, 2008, p.7).
}

A dimensão político-organizativa da categoria é, portanto, imprescindível no processo de formação de assistentes sociais, pois fortalece as dimensões essenciais da profissão e contribui para a construção e fortalecimento do Projeto Ético-Político. Conforme Duriguetto (2014, p.183) “[...] as prospectivas do fortalecimento da relação do Serviço Social brasileiro nas ações de mobilização e organização popular estão imbricadas com o constructo do projeto ético-político profissional." 


\title{
temporollis
}

Para que um projeto profissional se afirme na sociedade e ganhe solidez, é imperativo uma base profissional fortemente organizada, cuja organização política se consolida a partir da articulação das entidades representativas da categoria na construção de espaços coletivos que vislumbrem o fortalecimento dos princípios éticos e políticos do projeto profissional, gestados no bojo da profissão nas últimas décadas, o que demanda diálogo permanente com a base.

\begin{abstract}
É através dos fóruns consultivos e deliberativos destas entidades representativas que são tecidos os traços gerais do projeto, quando são reafirmados (ou não) determinados compromissos e princípios. Assim, subentende-se que o projeto ético-político (como uma projeção) pressupõe, em si mesmo, um espaço democrático, aberto, em construção e em permanente tensão e conflito. (BRAZ, 2008, p.6).
\end{abstract}

Nesta direção, é válido dizer que a participação em espaços de construções coletivas que contribuam para o delineamento e robustecimento da dimensão político-organizativa, contribui de forma inconteste para o fortalecimento do projeto ético- político e, tão logo, da qualificação da formação e exercício profissional.

É neste entorno que o projeto de formação profissional hegemônico ganha concretude e é delineado nas Diretrizes Curriculares da ABEPSS de 1996, a partir de amplo debate da categoria profissional, calcado na perspectiva crítica dialética, no entendimento de que a formação de um novo ethos profissional do/a assistente social, pode alavancar a profissão no compromisso com a classe trabalhadora rumo à outra sociabilidade, numa visão de Formação Profissional para além de mercado, mas para a vida social.

\section{Diretrizes curriculares da ABEPSS: sustentáculo ético-político para formação profissional}

As DCs se configuram como paradigma de valores éticos e políticos para a Formação Profissional em Serviço Social, haja vista que

4 Conforme expresso nas Diretrizes Curriculares da ABEPSS, foi realizado entre 1994 e 1996, um amplo processo de debate e construção com toda a base da categoria profissional, a partir da realização de aproximadamente 200 oficinas locais nas 67 Unidades de Formação Acadêmicas filiadas à ABEPSS, 25 oficinas regionais e 2 nacionais. 
“[...] expressa uma concepção de ensino e aprendizagem calcada na dinâmica da vida social, o que estabelece os parâmetros para inserção profissional na realidade sócio-institucional." (ABEPSS, 1996, p. 7). Deste modo, este documento construído coletivamente por toda categoria se constitui como um marco histórico do Serviço Social Brasileiro, no que concerne à proposta de Formação Profissional em consonância com o PEP.

Faz-se necessário dizer que, anterior às DCs de 1996, tínhamos, enquanto proposta para a formação de Assistentes Sociais no Brasil, o Currículo Mínimo de 1982, o qual também fora construído coletivamente pela categoria profissional e, apesar de conter equívocos teóricos e aspectos ainda muito sutis da perspectiva de Formação Profissional hegemônica e crítica, já representava um avanço no âmago profissional na direção da intenção de ruptura.

O Código de Ética de 1986 e o Currículo de 1982 são influenciados pela construção teórica de Gramsci, marcados pela explicitação da direção social da formação e prática profissional e o compromisso ético-político com a classe trabalhadora. A aproximação com a produção gramsciniana representa um grande avanço na intenção de ruptura, pois possibilita à categoria reavaliar sua retirada dos espaços institucionalizados, bem como potencializa a compreensão da contradição inerente ao fazer profissional e a realidade social e propicia a apreensão da coexistência entre hegemonia e contra-hegemonia, reconhecendo a profissão como contribuinte da construção de uma nova hegemonia. (SILVA, 2016, p. 37).

O Currículo Mínimo de 1982 já trazia elementos em consonância com a direção social, ética, política e ideológica que o Serviço Social assume na cena contemporânea, a qual é oriunda e gestada pela categoria a partir do Movimento de Reconceituação e toma concretude com a perspectiva de intenção de ruptura a partir da década de 1980.

Todavia, nesse período sócio-histórico, a profissão estava num processo inicial de construção e fortalecimento ético-político e galgava em passos maiores no sentido de se robustecer nas dimensões teórico-metodológica, técnico-operativa e ético-política, no compromisso e em sintonia com as lutas mais gerais da classe trabalhadora.

Nesse período [...] a questão da capacitação ética não estava colocada. É uma demanda em potencial que só 


\section{temporollis}

vai se desenvolver na década de 1990, no contexto de uma nova etapa de consolidação da ética profissional, marcada pela ampliação do debate e da produção teórica, bem como da capacitação ética de novos quadros profissionais, articulando a organização política à educação ética (BARROCO, 2004, p. 31).

É na década de 1990 que a profissão adquire, de forma mais avigorada, condições éticas e políticas de se forjar a ampliação do debate, da produção teórica, da capacitação ética de novos/as profissionais, como elementos fundamentais para a construção e organização política da categoria na defesa de um projeto de Formação Profissional atrelado a um projeto de profissão e, não obstante, também a um projeto societário - conforme já mencionado aprioristicamente.

Assim, objetivando avançar na discussão e fortalecimento do Serviço Social brasileiro na perspectiva de intenção de ruptura e na busca de superar os equívocos presentes no Currículo Mínimo de 1982 - tais como: a forte presença do ecletismo teórico, a fragilidade de produção do conhecimento sobre a ética - a profissão, pautada também na concepção de que a Formação Profissional deve ser compreendida como processo continuado que acompanhe o movimento dinâmico, contraditório e dialético da sociabilidade capitalista, iniciou o novo processo de revisão curricular, resultando nas Diretrizes Curriculares da ABEPSS de 1996 (SANTOS, 2007). Nesse sentido,

As DC reafirmam uma forma particular de compromisso com a formação profissional direcionada por valores e princípios no horizonte do projeto societário de superação da ordem burguesa, assumido por setores da categoria profissional e expresso em seu Código de Ética (1993). [...] Adota o referencial marxista na formação profissional, recuperando categorias centrais da teoria marxiana como o trabalho, ontologia e classes sociais (SANTOS, 2007, p. 65).

Deste modo, entendemos que a nova proposta de Formação Profissional de Assistentes Sociais no cenário brasileiro, está vinculada a uma formação para a vida social, entendendo-a, numa perspectiva de totalidade, que as contradições e os determinantes postos à realidade social, são inerentes ao modo de produção do capital. Com base nessa concepção, é que o/a profissional terá condições de se inserir na realidade socioinstitucional e atuar em consonância com a direção hegemônica da profissão, ou seja, atendendo aos interesses 


\section{tempordilis}

da classe trabalhadora e não da classe dominante e tendo como horizonte a transformação social.

Importante aqui destacar os principais elementos constitutivos das Diretrizes Curriculares de 1996, os quais são responsáveis pelo o que estamos avocando de novos princípios e valores ético-políticos da Formação Profissional para o Serviço Social. Estes foram construídos com base na dinâmica da realidade social e:

[...] assumidos pela questão social frente à reforma do Estado e às mudanças no âmbito da produção requerem novas demandas de qualificação do profissional, alteram o espaço ocupacional do assistente social, exigindo que o ensino superior estabeleça padrões de qualidade adequados. (ABEPSS, 1996, p. 4).

As DCs possuem quatro alicerces articulados entre si, que são os norteadores que garantem o direcionamento ético e político ao processo de Formação Profissional: I - Pressupostos da Formação Profissional; II - Princípios e Diretrizes da Formação Profissional; III Nova Lógica Curricular e IV - Observações e Recomendações.

O primeiro expressa a dinâmica da realidade e nos traz que os anos 1990 apresentaram expressivas transformações nos processos de produção e reprodução da vida social, as quais decorreram da reestruturação produtiva, da reforma do Estado, bem como das novas formas encontradas para o enfrentamento da questão social, dentre outros aspectos que também contribuíram para a alteração das demandas postas à profissão. (ABEPSS, 1996).

Nesse ínterim, o trabalho profissional do/a assistente social também passa por transformações, uma vez que as necessidades sociais dos/as usuários/as, que chegam em forma de demandas para o/a profissional, são condicionadas e determinadas pelo movimento da realidade do capital, não podendo ser concebidas fora desta relação. Assim, os pressupostos da Formação Profissional que balizam estas DCs são:

1 - O Serviço Social se particulariza nas relações sociais de produção e reprodução da vida social como uma profissão interventiva no âmbito da questão social, expressa pelas contradições do desenvolvimento do capitalismo monopolista.

2 - A relação do Serviço Social com a questão social - fun- 


\section{temporalis}

damento básico de sua existência - é mediatizada por um conjunto de processos sócio-históricos e teórico-metodológicos constitutivos de seu processo de trabalho.

3 - O agravamento da questão social em face das particularidades do processo de reestruturação produtiva no Brasil, nos marcos da ideologia neoliberal, determina uma inflexão no campo profissional do Serviço Social. Esta inflexão é resultante de novas requisições postas pelo reordenamento do capital e do trabalho, pela reforma do Estado e pelo movimento de organização das classes trabalhadoras, com amplas repercussões no mercado profissional de trabalho.

4 - O processo de trabalho do Serviço Social é determinado pelas configurações estruturais e conjunturais da questão social e pelas formas históricas de seu enfrentamento, permeadas pela ação dos trabalhadores, do capital e do Estado, através das políticas e lutas sociais (ABEPSS, 1996, p. 5, grifos nosso).

Nesse sentido, entendendo o significado social da profissão e que esta intervém no âmbito da questão social, tem-se, como requisição para o Serviço Social, um/a profissional com uma formação generalista, na perspectiva de totalidade da realidade social, para que tenha condições teórico-metodológica, ético-política e técnico-operativa de atuar nas diversas expressões da questão social, formulando respostas profissionais que possibilitem a construção de mediações, com vistas ao enfrentamento das demandas apresentadas.

Tal concepção de formação exige, necessariamente, abandonar as formas tradicionais e limitadas de atuação, convocando o/a assistente social para um olhar ampliado, ou seja, que consiga fazer leitura crítica da realidade social e suas contradições, entendendo também que sua atuação profissional é perpassada por diversas contradições, pois só assim terá possibilidades de intervir qualitativamente na vida do/a usuário/a, objetivando modificá-la e superando a perspectiva acrítica, a-histórica e fragmentada.

Nesse intervalo cabe destacar o significado e o compromisso sócio-histórico do Serviço Social, enquanto profissão construída na perspectiva de sujeito coletivo, histórico, político e crítico, capaz de fazer parte do complexo da totalidade da construção da organização das classes subalternas [...] que cotidianamente tem seus direitos negados e buscam o Serviço Social para viabi- 


\section{temporolis}

lizar o acesso a esses direitos, cabendo ao profissional compreender as demandas explícitas e as implícitas e construir uma proposta de intervenção coerente, estratégica, fundamentada e responsável ética e politicamente. (SILVA, 2016, p. 17).

Os princípios e diretrizes da Formação Profissional estabelecem, a nível nacional, uma base comum entre os cursos de graduação em Serviço Social e, a partir destas orientações gerais, as Instituições de Ensino Superior (IES), elaboram suas matrizes curriculares e delineiam seus projetos políticos pedagógicos. Dentre estes princípios destacamos: flexibilidade na organização dos currículos, ou seja, autonomia e possibilidade na definição das disciplinas, bem como de outros componentes curriculares; rigoroso trato histórico e teóricometodológico da realidade social e do Serviço Social; adoção da teoria social crítica e da perspectiva de totalidade social em suas dimensões de universalidade, particularidade e singularidade; construção das dimensões investigativa e interventiva, enquanto central para formação; indissociabilidade entre ensino, pesquisa e extensão; exercício e respeito ao pluralismo, entendendo-o enquanto elemento factual da vida social; ética enquanto princípio formativo; e, indissociabilidade entre estágio e supervisão acadêmica e profissional (ABEPSS, 1996).

Tais princípios consubstanciam e tonificam a proposta de formação profissional expressa nas DCs, na direção da construção e capacitação teórico-metodológica, técnico-operativa e ético-política para a:

1. Apreensão crítica do processo histórico como totalidade;

2. Investigação sobre a formação histórica e os processos sociais contemporâneos que conformam a sociedade brasileira, no sentido de apreender as particularidades da constituição e desenvolvimento do capitalismo e do Serviço Social no país;

3. Apreensão do significado social da profissão desvelando as possibilidades de ação contidas na realidade;

4. Apreensão das demandas - consolidadas e emergentes - postas ao Serviço Social via mercado de trabalho, visando formular respostas profissionais que potenciem o enfrentamento da questão social, considerando as novas articulações entre público e privado; 


\section{temporollis}

5. Exercício profissional cumprindo as competências e atribuições previstas na Legislação Profissional em vigor. (ABEPSS, 1996, p. 7).

Estes elementos expressam a maturidade e compromisso profissional, construído pela categoria nas últimas décadas, indo ao encontro do projeto profissional hegemônico, que delineia para a construção de outra sociabilidade, em que não haja a exploração do homem pelo homem 5 , dominação, opressão e quaisquer formas de injustiça social. Assim, aquiescemos com Silva (2016) quando aponta que:

A consolidação desta proposta acarreta transformações na identidade e [...] implica num outro modelo de formação profissional, trazendo outras possibilidades para a atuação profissional por meio da construção de uma nova identidade profissional [...], pois consideramos a identidade profissional uma construção social dinâmica, que se transforma na mesma medida em que ocorrem as transformações tanto das condições de ensino e aprendizagem, como as transformações sociais em que se dá sua construção histórica. Assim, concebemos o processo de formação como constituinte primário da construção desta identidade e suas dimensões. Podemos relacionar que a mudança no processo e nas condições da formação profissional, significa uma mudança na identidade profissional. (SILVA, 2016, p. 15).

Eis a necessidade de se fortalecer a proposta de Formação Profissional hegemônica, pois:

[...] esta concepção implica que o processo de trabalho do assistente social deve ser apreendido a partir de um debate teórico-metodológico que permita o repensar crítico do ideário profissional e, consequentemente, da inserção dos profissionais, recuperando o sujeito que trabalha enquanto indivíduo social. (ABEPSS, 1996, p. 8).

Para tanto, e já apontando aqui o terceiro alicerce constitutivo da nova lógica curricular, delineia que a efetivação deste projeto de formação está atrelada diretamente a um conjunto de conhecimentos indissociáveis, os quais devem perpassar todo o processo formativo, que se traduzem em três núcleos de fundamentação: Núcleo de

5 Entendido aqui enquanto ser social e não na concepção binária e patriarcal de gênero, disseminada e engendrada pela lógica da sociedade do capital. 
fundamentos teórico-metodológicos da vida social; Núcleo de fundamentos da particularidade da formação sócio-histórica da sociedade brasileira e Núcleo de fundamentos do trabalho profissional.

De acordo com a ABEPSS (1996), o primeiro núcleo é responsável pela discussão do ser social enquanto totalidade histórica, elucidando e analisando os componentes fundamentais da vida social para, posteriormente, particularizá-los nos outros dois núcleos. Constituem-se, de tal modo, enquanto eixos articuladores para a Formação Profissional na totalidade, desdobrando-se em áreas de conhecimento. Assim,

[...] remetem a um conjunto de conhecimentos indissociáveis para a apreensão da gênese, das manifestações e do enfrentamento da questão social, eixo fundante da profissão e articulador dos conteúdos da formação profissional. Portanto, os Núcleos mencionados não são autônomos nem subsequentes, expressando, ao contrário, níveis diferenciados de apreensão da realidade social e profissional, subsidiando a intervenção profissional. (ABEPSS, 1996, p. 9).

Tais núcleos se configuram como elementos que precisam trabalhar de forma articulada durante todo processo de formação, pois, somente assim, possibilitarão apreender a totalidade da realidade social. Logo, a Formação Profissional constitui-se de um conjunto de conhecimentos englobados nestes três núcleos, os quais apresentam suas particularidades e são essenciais para a formação de assistentes sociais na perspectiva da intenção de ruptura. Destacamos aqui,

[...] a centralidade do processo de formação na construção da leitura crítica da realidade social, necessária à atuação profissional, pois, é no processo de formação que se constitui o encontro da(o) estudante com os núcleos de fundamentos teórico-metodológicos da vida social, da particularidade da formação sócio-histórica da sociedade brasileira e do trabalho profissional. Este é o espaço primeiro em que se discute e se compreende todo o trajeto sócio-histórico e político da atuação da profissão na sociedade, suas transformações, perspectivas teórico-metodológica, ético-política, técnico-operativa, bem como suas relações com a estrutura social, realidade e o modo de desenvolvimento do capitalismo nas particularidades brasileiras. Essas compreensões constituem o arsenal de elementos que dão subsídios para uma prática coerente, reflexiva e comprometida com a transfor- 


\section{temporolis}

mação societária conforme projeto de profissão, delineado pela categoria na década de 1980/1990. (SILVA, 2016, p. 12).

Esta lógica curricular se constitui enquanto síntese do processo de construção da categoria profissional e possibilita robustecer a formação de profissionais assistentes sociais, na coerência com a direção social, ética e política do projeto profissional hegemônico. Por isso, a luta pela efetivação da formação tal como preconiza as DCs de 1996 é, sobretudo, a luta pelo direcionamento da profissão atrelada às lutas mais gerais dos/as trabalhadores/as.

O terceiro alicerce das DCs também aponta as matérias básicas necessárias para a Formação Profissional nesta perspectiva. Elas se configuram como expressões das áreas de conhecimentos, sistematizadas a partir dos núcleos de fundamentação, e podem se estender em disciplinas, seminários temáticos, oficinas/laboratórios, atividades complementares, bem como outros componentes curriculares (ABEPSS, 1996). Ademais, apresenta as atividades integradoras e indispensáveis para a Formação Profissional, a saber: Estágio Supervisionado e o Trabalho de Conclusão de Curso.

O estágio supervisionado, enquanto atividade curricular obrigatória, se configura a partir da inserção do/a estudante nos espaços sócio-ocupacionais do/a assistente social, com o fito de conhecer a dinâmica cotidiana do trabalho profissional. É o momento de aproximação com a realidade deste cotidiano e possibilita identificar as demandas postas e tecer reflexões acerca das diversas expressões da questão social que perpassam o campo de estágio. Demanda supervisão direta de assistente social (supervisor/a de campo e acadêmico/a), ambos regularmente inscritos no CRESS e em pleno gozo de suas atividades profissionais, no espaço sócio-ocupacional configurado como campo de estágio e unidade de formação acadêmica, respectivamente.

O estágio supervisionado no curso de Serviço Social apresenta como uma de suas premissas oportunizar ao(a) estudante o estabelecimento de relações mediatas entre os conhecimentos teórico-metodológicos e o trabalho profissional, a capacitação técnico-operativa e o desenvolvimento de competências necessárias ao exercício da profissão, bem como o reconhecimento do compromisso da ação profissional com as classes trabalhadoras, neste contexto político-econômico-cultural 


\section{tempordilis}

sob hegemonia do capital. (ABEPSS, 2010, p. 14).

A realização do estágio, pautada na perspectiva da Política Nacional de Estágio (PNE) elaborada pela ABEPSS (2010) significa, sobretudo, a defesa do Projeto Ético-Político do Serviço Social, bem como uma política de resistência às investidas do capital, visto que, o ideário neoliberal cada vez mais tende a deteriorar, mercantilizar e flexibilizar a educação, o que tem rebatimentos no nosso processo de Formação Profissional. Destarte, o fortalecimento desta coeva política, que é resultado de um longo debate e construção coletiva a partir de profícuos diálogos com a base da categoria, contribui na direção da qualificação da formação e exercício profissional.

O Trabalho de Conclusão de Curso - também componente curricular obrigatório para obtenção do diploma do curso de graduação em Serviço Social - deve expressar a síntese de todo processo formativo do/a estudante, pois é o trabalho no qual "[...] o aluno sistematiza o conhecimento resultante de um processo investigativo, originário de uma indagação teórica, preferencialmente gerada a partir da prática do estágio no decorrer do curso." (ABEPSS, 1996, p. 19). Esta sistematização, enquanto uma monografia científica elaborada pelo/a estudante sob orientação de um/a professor/a e avaliada pela banca examinadora, deve expressar os conhecimentos construídos ao longo do curso acerca das dimensões teórico-metodológica, ético-política e técnico-operativa.

O quarto e último elemento norteador das Diretrizes Curriculares são as observações e recomendações, que aludem sobre: carga horária mínima de duração para o curso de graduação em Serviço Social (3.000 horas com duração de 4 anos); tempo mínimo de duração do curso (8 semestres), sendo o tempo máximo de integralização de até $50 \%$ sobre a duração do mesmo; autonomia das instituições sobre a indicação de mecanismos de aproveitamento ou reconhecimento de estudos realizados em cursos pelo/a estudante, seja no âmbito da graduação ou da pós-graduação; garantia maior de carga horária para as disciplinas específicas de Serviço Social; necessidade do mesmo padrão de qualidade para cursos diurnos e noturnos; destinação nos currículos plenos de parte da carga horária total para atividades complementares; orientação acerca da carga horária do estágio supervisionado, a qual deve ter, no mínimo, 15\% da carga horária mínima do curso, ou seja, 450 horas, considerando as 3.000 horas para integralização do curso. 


\section{temporollis}

Os principais aspectos aqui apresentados norteiam a implantação das DCs da ABEPSS de 1996 e a proposta de Formação Profissional, contida neste documento, expressa sintonia com a direção social da profissão na intenção de ruptura, a qual requer uma formação para a vida social e que supere a fragmentação do processo de ensino-aprendizagem, permitindo uma intensa convivência acadêmica entre docentes, discentes e sociedade. (ABEPSS, 1996).

As reflexões ora tecidas são no sentido de ratificar a necessidade do fortalecimento das DCs enquanto balizador para a Formação Profissional em Serviço Social na contemporaneidade, entendendo que se faz fundamental o compromisso com a vigília do processo de formação, sobretudo em tempos acirrados de precarização, sucateamento e mercantilização da Educação, sobretudo a superior, tendo em vista que:

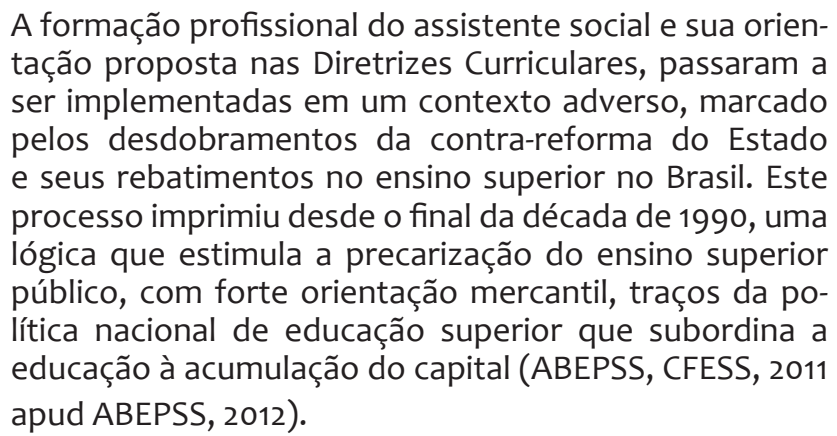

Como evidências deste processo de mercantilização do ensino, temos a Lei de Diretrizes e Bases da Educação (LDB), de 20 de novembro de 1996, a qual traz, em seu título III sobre o Direito à Educação e do Dever de Educar, no Art. $7^{\circ}$ que: "O ensino é livre à iniciativa privada" e, mais especificamente no capítulo IV que trata da Educação Superior, têm-se mais elementos que ratificam essa proposta de educação enquanto mercadoria como o Art. 45, por exemplo, alude que instituições privadas podem oferecer Ensino Superior. Este fato contraria, inclusive, o Art. 205 da Constituição Federal de 1988 que diz que a Educação é direito de todos/as e dever do Estado, logo temos que a Educação é direito social.

Além disso, a LDB permite a oferta de Educação na modalidade a Distância (EAD), o que significa a intensificação do processo de precarização da Educação Superior no Brasil e, no âmbito do Serviço Social, causa rebatimentos nefastos ao Projeto de Formação Profis- 


\section{tempordilis}

sional contido nas DCs da ABEPSS, resultando na ampliação do número de assistentes sociais formados/as por currículos flexibilizados, na dificuldade de efetivar o tripé ensino-pesquisa e extensão, e também na formação de exército industrial de reserva no bojo profissional, além de um processo de retomada da construção de perfil profissional tecnicista.

O contexto de desmonte, mercantilização e sucateamento da educação, apresenta sérios prejuízos e riscos ao projeto de formação aqui discutido e defendido, pois a estrutura de ensino nos moldes mercadológicos e neoliberal atende aos interesses do capital no sentido de formação de profissionais meramente técnicos/as e executores/as das políticas públicas para o mercado, e no Brasil atende aos ditames dos organismos internacionais. Ademais, "esta expansão desordenada e sem critérios, traz grandes desafios para o projeto de formação profissional e para implementação das Diretrizes Curriculares, para o exercício profissional e para as relações de trabalho e condições salariais" (CFESS, 2011).

Outro aspecto que se coloca como desafiador para a implementação e fortalecimento da Formação Profissional orientada pelas DCs de 1996, são as Diretrizes aprovadas pelo CNE//MEC (2000), as quais de acordo com lamamoto, sofrem:

[...] forte descaracterização no que se refere à direção social da formação profissional, aos conhecimentos e habilidades considerados essenciais ao desempenho do assistente social. Assim, por exemplo, no perfil do bacharel em Serviço Social constava '[.... profissional comprometido com os valores e princípios norteadores do Código de Ética do Assistente Social', o que foi retirado e substituído por 'utilização dos recursos da informática.' $\mathrm{Na}$ definição das competências e habilidades, é suprimido do texto legal o direcionamento teórico-metodológico e histórico para a análise da sociedade brasileira [...] Também os tópicos de estudos foram totalmente banidos do texto oficial em todas as especialidades. [...] Este corte significa, na prática, a dificuldade de garantir um conteúdo básico comum à formação profissional no país. O conteúdo da formação passa a ser submetido à livre-iniciativa das unidades de ensino condizentes com os ditames do mercado [...]. (IAMAMOTO, 2014, p. 617, grifos da autora).

As alterações nas DCs, realizadas pelo MEC, obstaculizam a 


\title{
temporollis
}

concepção de Formação Profissional defendida pela categoria de Serviço Social, se configurando como uma afronta ética e política a todo legado que a profissão construiu nas últimas décadas, na perspectiva de uma formação que, de fato, possibilite uma atuação profissional de qualidade, no sentido de atender às reais necessidades dos/as usuários/as do serviço numa perspectiva de emancipação política.

Por isso, essa realidade nos coloca a preocupação com o processo de Formação Profissional, o qual deve compreender a atuação para além da operacionalização das políticas públicas, justamente por se tratar de uma profissão que compreende a sociedade de classes, os limites destas políticas dentro desta estrutura de sociedade e, também, por compreender a ação transformadora dos seres humanos na produção e superação da ordem do capital. (SILVA, 2016).

Nesse ínterim, são muitos os desafios e limites postos, assim, defender a proposta de Formação Profissional expressa pelas DCs da ABEPSS de 1996, significa nos colocarmos no contrafluxo do capital. Portanto, o atual cenário nos exige formular estratégias e nos fortalecer coletivamente, no sentido de avigorar nossa luta em defesa dos princípios éticos fundamentais e, consequentemente, do projeto de Formação Profissional hegemônico.

\begin{abstract}
A necessidade de retomada da discussão das Diretrizes Curriculares, vem sendo demandada nos encontros da categoria, no sentido de enfrentar o aligeiramento da formação e o avanço das forças neoconservadoras que atravessam o Serviço Social, reduzindo à formação um conjunto de repasses de conteúdos e procedimentos de intervenção numa direção tecnicista e meramente funcional aos interesses do mercado. (ABEPSS, 2012).
\end{abstract}

Destarte, as entidades da categoria historicamente têm construído espaços coletivos de discussões e construções que convergem com a direção social da profissão. Tais espaços expressam e tonificam a construção coletiva da categoria em torno da proposta de formação a qual se norteia:

[...] pela defesa da universidade pública, gratuita e de qualidade, direcionada aos interesses da coletividade e enraizada na realidade regional e nacional; a universidade que cultiva a razão crítica e o compromisso com os valores universais, coerente com sua função pública, não limitada e submetida a interesses particulares exclusivos de determinadas classes ou frações de classes; 


\section{temporolis}

uma instituição a serviço da coletividade, que incorpore os dilemas regionais e nacionais como matéria da vida acadêmica, participando da construção de respostas aos mesmos no âmbito de suas atribuições. (IAMAMOTO, 2014, p. 625).

As entidades representativas da categoria: CFESS/CRESS, ABEPSS e ENESSO, numa relação de articulação política, têm sido partícipes aguerridas desta construção coletiva e, calcadas na defesa desta perspectiva de educação, tem construído a base de legitimação no âmago profissional. Em constante articulação, tais entidades têm protagonizado, historicamente, ações que evidenciam o compromisso com o debate de Formação Profissional, alinhado à defesa da classe trabalhadora e na luta pela transformação da atual sociabilidade do capital.

Há longas datas, esta pauta tem ganhado concretude e sido foco de discussão nos diferentes eventos da profissão; sobremaneira, na reafirmação da necessária consonância do ensino universitário com o projeto profissional, do respeito à autonomia e presença política do Movimento Estudantil de Serviço Social e da incansável luta pela implantação das DCs da ABEPSS (1996), em detrimento das propostas institucionais a partir das DCs aprovadas pelo CNE/MEC (2000), fundamentadas na lógica da contrarreforma universitária.

Nesta direção, a vigília em defesa do projeto profissional tem sido tarefa das entidades da categoria que, articuladas e alinhadas politicamente, têm construído espaços de debates com a base, no sentido de disseminar e fortalecer tal projeto. Exemplo dessa unidade é o "Plano Nacional de Lutas em Defesa da Formação e do Trabalho Profissional" que contém atividades a serem construídas coletivamente entre as entidades, objetivando fortalecer o projeto de formação em voga. Neste ínterim, é salutar aqui mencionar o Projeto ABEPSS Itinerante, que tem por objetivo:

Fortalecer as estratégias político-pedagógicas de enfrentamento à precarização do ensino superior, por meio da difusão ampla dos princípios, conteúdos e desafios colocados para a consolidação das Diretrizes Curriculares como instrumento fundamental na formação de novos profissionais, na direção do plano de lutas em defesa do trabalho e da formação e contra a precarização do ensi- 


\section{temporalis}

no superior. (ABEPSS, 2012) 6.

Tal projeto tem sido um importante desafio para a ABEPSS, diante da tarefa precípua de ampliar os debates e reforçar os princípios das Diretrizes Curriculares na direção social que a profissão construiu nos últimos 30 anos, articuladamente com as Unidades de Formação Acadêmicas (UFAs), a ENESSO, os CRESS e o CFESS na materialização dessa atividade. Assim, o projeto ABEPSS Itinerante tem sido uma estratégia política das entidades da categoria para o fortalecimento das DCs em face da atual contextura tão adversa para a formação profissional na perspectiva crítica e emancipatória, defendida por estas entidades.

Tendo em vista o atual contexto avassalador de desmonte, retrocesso, precarização, mercantilização de direitos e, dentre eles a educação, é imprescindível que as entidades da categoria se fortaleçam cada vez mais na direção de uma ação política e coletiva; tonificando a articulação entre elas para a luta em prol de uma educação pública, gratuita, laica, de qualidade, socialmente referenciada e de um projeto de Formação Profissional na consonância com as Diretrizes Curriculares da ABEPSS de 1996.

Nesse sentido, o fortalecimento desta articulação política deve estar cotidianamente na "ordem do dia" das entidades, haja vista que é esta relação de unidade que tem possibilitado a manutenção da direção do projeto coletivo defendido hegemonicamente pela profissão (RAMOS, 2011). Aliás, nestes tempos tão "temerosos" que temos vivenciado, a luta pela afirmação do legado crítico construído nas últimas décadas pela profissão no cenário brasileiro, deve ser uma tarefa imperativa e deve estar na agenda de luta de todos/as nós que acreditamos no projeto emancipatório do Serviço Social brasileiro.

\section{Considerações Finais}

O tempo presente perpetrado pelo avanço do neoconservadorismo, da barbarização da vida social, por retrocessos no campo dos direitos conquistados historicamente pela classe trabalhadora, por uma ofensiva à organização política e coletiva, nos coloca em condição permanente de enfrentamento aos ditames do capital e nos con-

6 Síntese do Objetivo Geral do Projeto ABEPSS Itinerante, contido no site da ABEPSS. 


\section{temporalis}

voca, cotidianamente, à luta e resistência na construção de estratégias mais radicais no enfrentamento da 'toupeira' ainda presente que vem por debaixo da terra e irrompe de forma surpreendente nos seus mais variados formatos e conteúdos políticos, econômicos, éticos e estéticos as condições de vida e trabalho. (CFESS, 2016).

Acirram-se os desafios à construção permanente e materialização deste projeto profissional coletivo que é ético e politicamente impelido pelas lutas da classe trabalhadora que impulsionam possibilidades da emancipação humana, da plena expansão dos indivíduos sociais, da socialização da riqueza econômica, política e cultural, conforme preconizam nossos princípios e valores éticos fundamentais. Essa luta nos convida à rebeldia e significativa dose de pessimismo da razão e otimismo da vontade para construirmos as mediações necessárias para o robustecimento do projeto profissional hegemônico do Serviço Social Brasileiro e, não obstante, fortalecer a proposta de Formação Profissional em consonância com a direção social, ética e política, contida nas DCs da ABEPSS.

Acreditamos ser mediações possíveis, considerando os 80 anos de Serviço Social no Brasil, 70 anos de ABEPSS e 20 anos de Diretrizes Curriculares, que demarcam, além de comemorações das conquistas históricas da profissão, acúmulos de forças para lutar e resistir, no sentido da reafirmação e fortalecimento dos nossos valores éticos e políticos no compromisso com as lutas mais gerais dos/as trabalhadores/as e na construção de ações conjuntas da categoria com a base popular visando, de fato, a construção de outra ordem social - o que demanda quinhões de ortodoxia na implantação e implementação das DCs, a fim de formar profissionais com sólida fundamentação téorico-metodológica, ético-política e técnico-operativa.

\section{REFERÊNCIAS}

ABEPSS. Associação Brasileira de Ensino e Pesquisa em Serviço Social. Diretrizes gerais para o curso de Serviço Social: com base no currículo mínimo aprovado em assembléia geral extraordinária de 8 de novembro de 1996. Rio de Janeiro: ABEPSS, 1996.

. Política nacional de estágio da Associação Brasileira de Ensino e Pesquisa em Serviço Social. Brasília, DF: CFESS/ABEPSS, 2010. 


\section{temporollis}

. Projeto ABEPSS Itinerante: as diretrizes curriculares e o projeto de formação profissional do serviço social. Brasília, DF: ABEPSS, 2012. Disponível em: <http://www.abepss.org.br/projeto-abepss-itinerante-18>. Acesso em: 5 ago. 2016.

BARROCO, Maria Lúcia da Silva. A inscrição da ética e dos direitos humanos no projeto ético-político do Serviço Social. Serviço Social \& Sociedade. Serviço Social: formação e projeto político. São Paulo, n.79, p. 27-42, set. 2004.

BRAZ, Marcelo. Notas sobre o projeto ético-político do serviço social. In: CRESS 7a Região. (Org.). Assistente social: ética e direitos. 5. ed. Rio de Janeiro: Daugraf, 2008, (Coletânea de leis e resoluções, v. 1).

CFESS. Conselho Federal de Serviço Social. Manifesto CFESS, ABEPSS e ENESSO. Brasília, DF: CFESS, 2011. Disponível em: <http://www.cfess. org.br/arquivos/cartaentidades_CFESS-ABEPSS-ENESSO_FINAL.pdf>. Acesso em: 5 ago. 2016.

CFESS, 2016.

. Apresentação. Agenda Assistente Social 2017. Rio de Janeiro:

DURIGUETTO, Maria Lúcia. Movimentos sociais e Serviço Social no Brasil pós-anos 1990: desafios e perspectivas. In: . ABRAMIDES, Maria Beatriz. (Orgs.). Movimentos sociais e Serviço Social: uma relação necessária. São Paulo: Cortez, 2014.

IAMAMOTO, Marilda Villela. Renovação e conservadorismo no Serviço Social: ensaios críticos. 2. ed. São Paulo: Cortez, 1994.

. A formação acadêmico-profissional no Serviço Social brasileiro. Serviço Social e Sociedade, São Paulo, v. 120, p. 609-639, out/dez. 2014.

PAULO NETTO, José. A construção do projeto ético-político do serviço social. Centro Português de Investigação em História e Trabalho 
Social, Lisboa, 1999. Disponível em: <http://www.cpihts.com/PDF03/ jose\%2opaulo\%2onetto.pdf >. Acesso em: 19 ago. 2016.

. Ditadura e Serviço Social: uma análise do serviço social no Brasil pós-64. São Paulo: Cortez, 2010.

RAMOS, Sâmya Rodrigues. A importância da articulação entre ABEPSS, conjunto CFESS/CRESS e ENESSO para a construção do projeto ético-político do Serviço Social Brasileiro. Temporalis, Brasília, DF, v. 2, n. 22, p. 113-122, jul/dez. 2011. Disponível em: <http://periodicos.ufes.br/ temporalis/article/view/1727/1601>. Acesso em: 25 ago. 2016.

SANTOS, Tiago Barbosa. A participação política dos estudantes de Serviço Social na defesa e consolidação da direção social da formação: a práxis política dos estudantes e a relação com a formação profissional. 2007. 279 f. Trabalho de Conclusão de Curso (Graduação em Serviço Social) -- Faculdade de Serviço Social, Pontifícia Universidade Católica, São Paulo, 2007.

SILVA, Letícia Rodrigues. A dimensão ético-política do Serviço Social e o ensino a distância: avanços e retrocessos na formação profissional. 2016. 101 f. Trabalho de Conclusão de Curso (Graduação em Serviço Social) -- Universidade Federal do Triângulo Mineiro, Uberaba, 2016. 


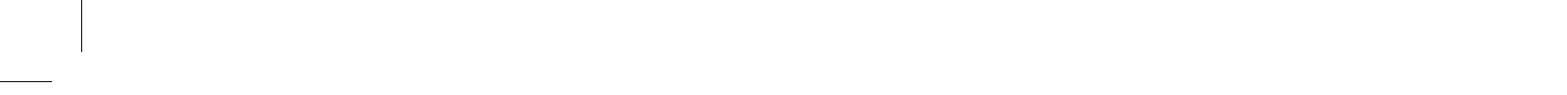

